Article

\title{
Biofilm-associated Agr and Sar quorum sensing systems of methicillin-resistant Staphylococcus aureus are inhibited by fruit extracts of Illicium verum
}

P. Sankar Ganesh ${ }^{1 *+}$, Krishnamurthy Veena ${ }^{1+}$, Koneti Iswamy ${ }^{1}$, S. Suvaithenamudhan ${ }^{2}$, Amudhan Murugesan ${ }^{3}$, Irudhayaraj J. Vimali ${ }^{1}$, Arumugam V. Ravi ${ }^{4}$, Sivakumar Shanmugam ${ }^{5}$, Dinakar Challabathula6, Samuthira Nagarajan7, Esaki M. Shankar ${ }^{1^{*}}$

1 Division of Infectiology and Medical Microbiology, Department of Life Sciences, School of Life Sciences, Central University of Tamil Nadu, Neelakudi, Thiruvarur 610 005, India.

2 Department of Bioinformatics, School of Life Sciences, Bharathidasan University, Thiruchirappalli 620024 , Tamilnadu, India

3 Department of Microbiology, Government Theni Medical College and Hospital, Theni 625 531, India.

4 Department of Biotechnology, Alagappa University, Karaikudi 630 003, India.

5 Department of Organic Chemistry, School of Chemistry, Madurai Kamaraj University, Madurai 625 021, India

6 Division of Plant Biology and Stress Physiology, Central University of Tamil Nadu, Neelakudi, Thiruvarur 610 005, India.

7 Division of Organic Synthesis and Organic Electronics, Department of Chemistry, Central University of Tamil Nadu, Neelakudi, Thiruvarur 610 005, India.

${ }^{\dagger}$ Equal contribution by the authors

*Corresponding Authors: Esaki M. Shankar (shankarem@cutn.ac.in) or P. Sankar Ganesh

(p_sankarganesh@hotmail.com)

\begin{abstract}
Background: Staphylococcus aureus (S. aureus) is an opportunistic pathogen and a predominant cause of life-threatening nosocomial infections. Drug resistance in S. aureus is attributed to production of biofilm, which is controlled largely by bacterial quorum sensing (QS) systems. Methodology: In vitro analysis of biofilm inhibition assay was performed using crystal violet staining assay, swarming motility, light microscopy and growth curve analyses. Identification of the major constituents of I. verum fruit extract was performed by GC-MS. Ligand-protein interaction was analyzed by molecular docking investigations. Results: The methanol extract of $I$. verum inhibited the growth of MRSA at the concentration of $4.8 \mathrm{mg} / \mathrm{ml}$. At the sub-inhibitory concentration $(2.4 \mathrm{mg} / \mathrm{ml})$, the extract showed significant reduction in biofilmogenesis. Light microscopy analysis confirmed the antibiofilm activity as well as the efficacy in disturbing biofilm architecture. A reduced swarming motility was observed at the lowest concentration of $2.4 \mathrm{mg} / \mathrm{ml}$. GC-MS analysis revealed anethol (AL) as the major constituent. The molecular docking analysis attributes the antibiofilm activity to an active ligand $\mathrm{AL}$, which strongly interacted with the active site residues of AgrA and SarA proteins of S. aureus. Conclusion: We report the activities of $I$. verum to be immensely interfering with QS system and biofilm formation in MRSA.
\end{abstract}

Key words: AgrA protein; biofilm; MRSA; quorum sensing; SarA protein; swarming 


\section{Introduction}

Staphylococcus aureus (S. aureus) is a Gram-positive opportunistic pathogen, which causes various recalcitrant infections in humans [1]. In health care settings, S. aureus is a documented cause of a wider spectrum of infections ranging from minor skin and soft-tissue infections such as cellulitis, impetigo, furuncle to highly invasive disease including bacteremia, endocarditis, sepsis, osteomyelitis, ventilatorassociated pneumonia etc [2]. S. aureus is one of the major pathogens associated with surgical-site infections, and can cause urinary tract infections involving indwelling medical devices $[3,4]$. S. aureus is predominantly responsible for community-acquired infections, and in hospitalized patients represents a serious challenge to treatment. S. aureus is notorious owing to its ability to resist various antibiotics $[5,6]$. It uses oligopeptides as signaling molecules, which play an important role in the production of secreted virulence factors and formation of biofilms in host tissues [7]. The quorum sensing (QS) system of $S$. aureus is controlled by two pathways namely the staphylococcal accessory regulator (sar) and accessory global regulator (agr) cascades. The agr QS system is composed of the agrBDCA operon, which utilizes oligopeptide as signaling molecules, and regulates the expression of secreted virulence factors in S. aureus [8]. Similarly, SarA protein is a global control QS cascade that controls virulence factors and biofilm formation in S. aureus.

Biofilms are conglomerate microbes that grow often on indwelling medical devices. S. aureus reportedly produces a multilayered biofilm encoded by the icaADBC operon responsible for the synthesis of extracellular matrix consisting of lipoproteins (autolysin), lipids, polysaccharide intercellular adhesion (PIA) and nucleic acids [9]. Biofilm matrix is resistant to conventional antibiotics, and also helps the bacteria to evade from protective host immune responses [10]. The currently available antibiotics appear to lose efficacy and are believed to augment bacterial pathogenesis owing to production of secreted virulence factors and biofilm [11,12]. Hence, there is an immense necessity for potent QS inhibitors (QSIs) preferably from natural resources. Secondary metabolites of plants attribute to heal many bacterial, fungal and viral infections [13], and a plethora of such secondary metabolites appear to inhibit the QScontrolled virulence factors and biofilms.

Illicium verum Hook.f. (I.verum) belonging to family Illiaceae, is an aromatic evergreen tree that bears a purple-red flower and a star-shaped fruit, commonly known as star anise, often used as a spice in the tropical and subtropical world [14]. I. verum has potent antimicrobial, stimulant, antiviral, anticancer, anti-oxidative, rheumatism, otalgia, antiseptic and diuretic properties [15]. However, the exact constituent responsible for the anti-QS and antibiofilm activities in I.verum remains ambiguous. Here, we determined the QS-controlled secreted virulence factors and antibiofilm properties of I. verum against MRSA both in vitro and in silico analyses.

\section{Results}

\subsection{Biochemical characterization and antimicrobial susceptibility of S. aureus}

Strains of S. aureus (SA-01 and SA-02) were obtained from the medical repositories of the Government Theni Medical College, Theni. Based on morphological characterization of clinical isolates, distinct morphotypes were observed on selective media. Golden yellow color colonies with significant staphyloxanthin pigment production were observed on mannitol salt agar. According to Patricia (2014), the clinical isolates were identified as $S$. aureus by various standard biochemical characterization tests such as methylene red, Voges-Proskauer, urease, gelatin hydrolysis, protease hydrolysis, coagulase tests and were found to be positive (Table S1). 
Table 1: Antibiogram profiles of S. aureus (SA-01) and S. aureus (SA-02) strains employed in the investigation.

\begin{tabular}{clcccc}
\hline S. No & Antibiotics & \multicolumn{2}{c}{ SA-01 } & \multicolumn{2}{c}{ SA-02 } \\
\cline { 3 - 5 } & & SD value & R/S & SD value & R/S \\
\hline 1 & Penicillin G & - & $\mathrm{R}$ & $31.3 \pm 1.1$ & $\mathrm{~S}$ \\
2 & Methicillin & - & $\mathrm{R}$ & $24 \pm 1.15$ & $\mathrm{~S}$ \\
3 & Amoxycillin & - & $\mathrm{R}$ & $36.3 \pm 0.5$ & $\mathrm{~S}$ \\
4 & Ampicillin & $0.8 \pm 0.1$ & $\mathrm{R}$ & $34.1 \pm 0.15$ & $\mathrm{~S}$ \\
5 & Colistin & - & $\mathrm{R}$ & - & $\mathrm{R}$ \\
6 & Tigecyclene & $15.6 \pm 0.5$ & $\mathrm{IM}$ & $20.6 \pm 0.5$ & $\mathrm{~S}$ \\
7 & Impenem & $10 \pm 0$ & $\mathrm{R}$ & $11 \pm 1.73$ & $\mathrm{R}$ \\
8 & Kanamycin & - & $\mathrm{R}$ & $19 \pm 1$ & $\mathrm{~S}$ \\
9 & Ciprofloxacin & - & $\mathrm{R}$ & $8.6 \pm 0.5$ & $\mathrm{R}$ \\
10 & Streptomycin & - & $\mathrm{R}$ & $14 \pm 0$ & $\mathrm{IM}$ \\
11 & Ceftazidime & - & $\mathrm{R}$ & $12.6 \pm 0.5$ & $\mathrm{R}$ \\
12 & Cephalothin & - & $\mathrm{R}$ & $38.8 \pm 1.04$ & $\mathrm{~S}$ \\
13 & Chloramphenicol & $16 \pm 1.7$ & $\mathrm{R}$ & $19 \pm 0$ & $\mathrm{~S}$ \\
14 & Gentamicin & & $\mathrm{R}$ & $20.3 \pm 0.5$ & $\mathrm{~S}$ \\
\end{tabular}

Note: “R"- Resistant, “S”- Sensitive, “IM"- Intermediate, SD

Antibiotic susceptibility test was determined by conventional Kirby-Bauer's disk diffusion method for both multidrug-sensitive and resistant $S$. aureus. SA-01 was resistant to all the $\beta$-lactam antibiotics tested, and also to streptomycin, colistin, kanamycin, ceftazidime, ciprofloxacin, impenem, cephalothin and gentamicin, but sensitive to chloramphenicol and tigecycline. Similarly, SA-02 was sensitive to all the antibiotics tested except ciprofloxacin, colistin and imipenem (Figure 1 and Table 1).
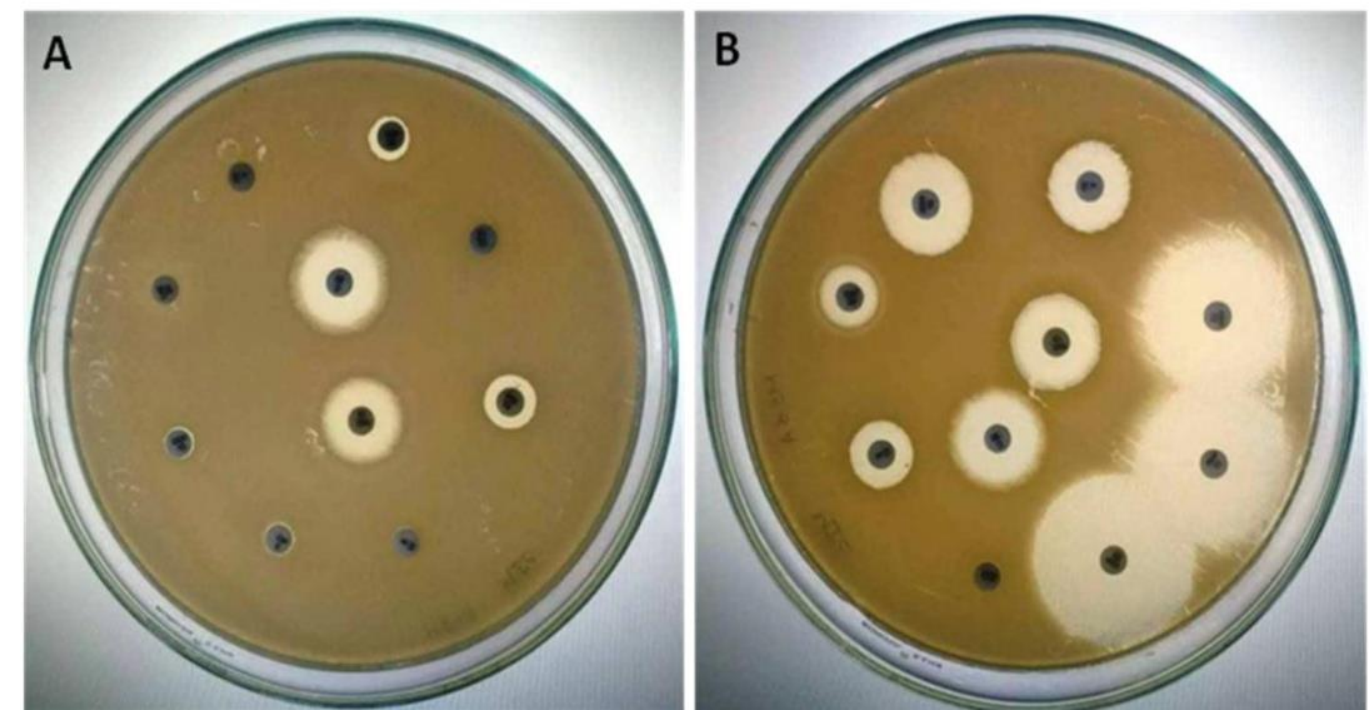

Figure 1: Antibiogram profile of test $S$. aureus strains by Kirby-Bauer disk diffusion method A) $S$. aureus PA-01 B) S. aureus PA-02. 


\subsection{At a lowest concentration of $4.8 \mathrm{mg} / \mathrm{ml}$, I. verum methanol extract inhibited the growth of MRSA}

The antibacterial activity of star anise (I. verum fruit) methanol extract was evaluated by using a two-fold serial dilution method ranging from $9.6-0.01875 \mathrm{mg} / \mathrm{ml}$. Methanol extract of $I$. verum fruit potentially inhibited the growth of MRSA strain SA-01 at the lowest concentration of $4.8 \mathrm{mg} / \mathrm{ml}$ (Table S2). Therefore, the sub-MIC of extract of I. verum fruit was used for determining the anti-biofilm activity of SA-01 strain.

\subsection{I. verum extract inhibited QS-dependent virulence and biofilm formation in MRSA at the sub-MIC level.}

The inhibitory effect of I. verum fruit extract on biofilm forming ability in SA-01 strain was evaluated using static microtitre plate method by staining with $0.1 \%$ crystal violet. Spectrophotometric analysis revealed a maximum of $74 \%$ inhibition of biofilm formation with SA-01 at the concentration of $2.4 \mathrm{mg} / \mathrm{ml}(p \leq 0.005)$ (Figure 2A) without affecting the growth of MRSA. Similarly, the crude extract of $I$. verum inhibited biofilm formation in a dose-dependent manner (0.3-1.2mg) (Figure 2A).

Swarming motility is regulated by QS system that controls bacterial motility on viscous surfaces. Our study revealed that methanol crude extract of I. verum (fruit) potentially reduced swarming of MRSA at a lowest concentration of $2.4 \mathrm{mg} / \mathrm{ml}$ (Figure 2E). Without treatment, MRSA showed swarming (Figure 2D).


Figure 2: Effect of methanol crude extract of I. verum fruit on QS-regulated biofilm formation in MRSA (SA-01). A) Percentage of biofilm inhibition formed by MRSA strain represented by crystal violet staining for biomass and significant biofilm inhibition observed $(\mathrm{p}<0.001)$ in I. verum fruit treated cells. Biofilm matrix observed through light microscopy: B) Thick biofilm formation in the untreated (control) strain of MRSA (SA-01). C) Reduced biofilm matrix in I. verum fruit (methanol crude extract) -treated sample of MRSA (SA-01) compared to the control after $16 \mathrm{~h}$ incubation. Effect of I. verum on swarming in MRSA strain: (D) Without treatment (I. verum) of MRSA strain and (E) with I. verum $(2.4 \mathrm{mg} / \mathrm{ml})$ treatment 
of MRSA strain. Growth curve analysis: (F) S. aureus grown without (Control) and in the presence of $I$. verum fruit extract at the concentration of $2.4 \mathrm{mg} / \mathrm{ml}$.

Bacterial growth analysis of SA-01 both in the presence and absence of methanolic extracts of $I$. verum fruit was performed. Results revealed that crude extract did not inhibit the growth of bacterial cells at the lowest concentration of $2.4 \mathrm{mg} / \mathrm{ml}$ (Figure 2F).

Direct light microscopy analysis of the control group showed dense aggregates and confluent biofilm growth with diffuse extracellular polymers (Figure 2B) where as in case of I. verum (fruit extract) treated SA-01 strain we observed marked reduction in biofilm development at the sub-MIC level (Figure 2C). Together, we concluded that methanol extract of I. verum (fruit) potentially inhibits biofilm formation in the SA-01 strain.

\subsection{Gas Chromatography-Mass Spectroscopy (GC-MS) analysis}

Based on GC-MS analyses, the major compounds were identified as methanol extract of $I$. verum (fruit) (data not shown). Highest mass peak at 148.0888, contained a major ingredient AL (63 m/z), which likely exhibited anti-QS and antibiofilm activities against SA-01 (Figure 3), which was further confirmed by in silico analyses.

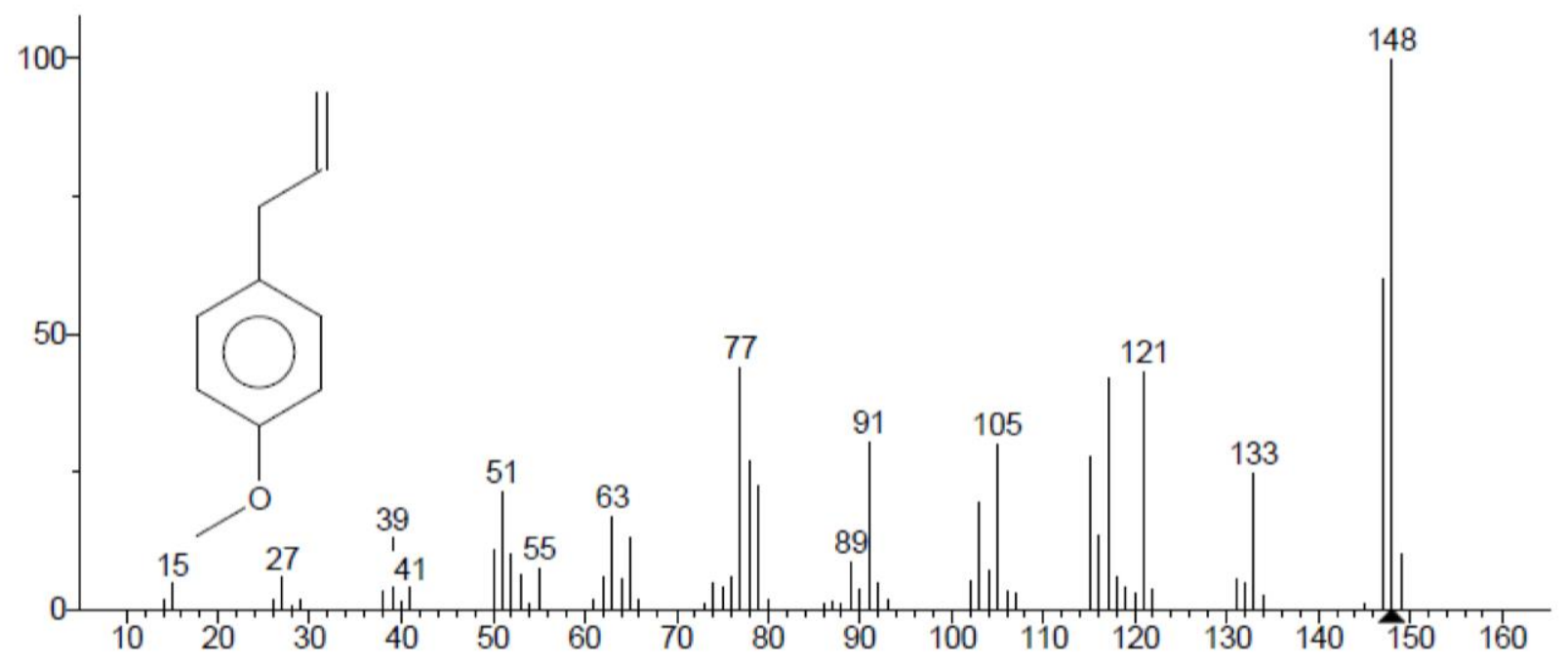

Figure 3: GC-MS analysis: Major constituent of anethole (AL) present in the methanol crude extract of I. verum fruit.

2.5. In silico analysis of quorum sensing inhibitory activity of I. verum and it's constituent anethol (AL) against MRSA

\subsubsection{Induced fit docking of MRSA AgrA and SarA with AL}

Induced fit docking results showed that the ligand AL (CID 637563) (Table 2) interacts with the active site residue LYS 146 of S. aureus AgrA. XP Glide score and IFD energy score of -4.692 and -232.42 $\mathrm{kcal} / \mathrm{mol}$ respectively (Table 3 ). Hydrogen bonding interacted amino acids along with their prime energy and their bond lengths were measured. This shows that the ligand was well bound to the active site of $S$. 
aureus AgrA. The ligand and its corresponding amino acid residue interactions with the hydrogen bond lengths are shown in Figure 4A, B and C.

Table 2: PubChem database details of anethole (https://pubchem.ncbi.nlm.nih.gov/)

\begin{tabular}{|c|c|c|c|c|c|c|c|}
\hline $\begin{array}{c}\text { Compoun } \\
\mathrm{d}\end{array}$ & $\begin{array}{c}\text { PubChem CID } \\
\text { and } \\
\text { Structure }\end{array}$ & $\begin{array}{l}\text { Molecula } \\
\mathrm{r} \text { formula }\end{array}$ & $\begin{array}{c}\text { Molecula } \\
\text { r weight } \\
\text { (g/mol) }\end{array}$ & $X \log P$ & $\begin{array}{l}\text { Hydrogen } \\
\text { Bond } \\
\text { Donor }\end{array}$ & $\begin{array}{l}\text { Hydrogen } \\
\text { Bond } \\
\text { Acceptor }\end{array}$ & $\begin{array}{c}\text { Rotationa } \\
1 \text { bonds }\end{array}$ \\
\hline Anethole & CID 637563 & $\mathrm{C}_{10} \mathrm{H}_{12} \mathrm{O}$ & 148.205 & 3.3 & 0 & 1 & 2 \\
\hline
\end{tabular}

Table 3: The interacted residues, XP Glide scores and IFD score in hydrogen bond interactions with distance between anethole of the S. aureus AgrA and SarA.

\begin{tabular}{|c|c|c|c|c|c|}
\hline \multirow{2}{*}{ PDB ID } & \multicolumn{5}{|c|}{ Anethole } \\
\cline { 2 - 6 } & Amino Acid & $\begin{array}{c}\text { Bond Length } \\
(\AA)\end{array}$ & $\begin{array}{c}\text { XP Glide Score } \\
\text { (kcal/mol) }\end{array}$ & IFD Score & $\begin{array}{c}\text { Prime } \\
\text { Energy }\end{array}$ \\
\hline $\begin{array}{c}\text { 4G4K } \\
\text { (S. aureus AgrA) }\end{array}$ & LYS 146 & 2.21 & -4.692 & -232.42 & -4554.59 \\
\hline $\begin{array}{c}\text { 2FNP } \\
\text { (S. aureus SarA) }\end{array}$ & GLN 164 & 1.98 & -2.723 & -258.90 & -5123.56 \\
\hline
\end{tabular}

IFD pose analysis that determines the binding affinity between S. aureus SarA and AL complexes showed that the AL (CID 637563) active ligand was found to bind efficiently with XP Glide score and IFD energy score of -2.723 and $-258.90 \mathrm{kcal} / \mathrm{mol}$ and formed two hydrogen bonds (Table 3). The active ligand AL forms two hydrogen bonds interactions with the active site residues GLN 164 and ARG 190 of $S$. aureus SarA with bond lengths of 1.98 and $1.85 \AA$, respectively (Figure 4D, E and F) (Table 3). The active ligand AL (CID 637563) with the two target proteins strongly interacted and bound with the active site residues of S. aureus AgrA and SarA proteins.
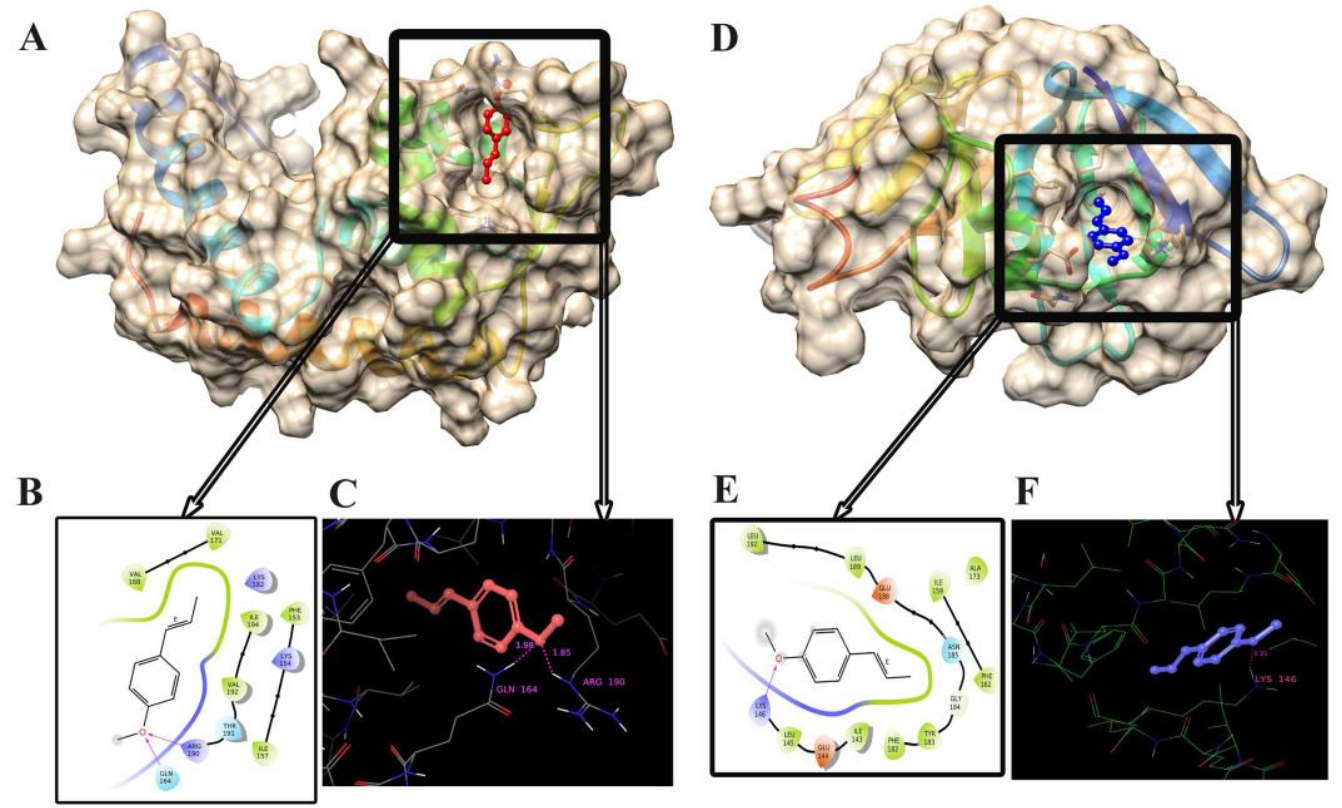
Figure 4: A) Docking snapshot of S. aureus AgrA (4G4K) with the ligand anethole (CID 637563) complex is shown. B) The 2D interaction profile of the ligand anethole employed in induced fit docking. C) The ligand is shown as ball and stick model (Blue). Residues involved in hydrogen bonding have been labeled with the hydrogen bond interactions in dotted pink lines and bond length have been shown in anethole. D) Docking snapshot of S. aureus SarA (2FNP) with the ligand anethole (CID 637563) complex is shown. E) The 2D interaction profile of the ligand anethole employed in induced fit docking. F) The ligand is shown as ball and stick model (Red). Residues involved in hydrogen bonding have been labeled with the hydrogen bond interactions in dotted pink lines and bond length have been shown in anethole.

\subsubsection{Molecular dynamics simulations}

We observed that throughout the simulation period (100 ns) (Figure 5C and D), the protein backbone of the $S$. aureus SarA (2FNP) was slightly deviated and flexible when compared with $S$. aureus AgrA (4G4K) with their maximum RMSD values at 0.5 and $0.1 \mathrm{~nm}$, respectively (Figure 5A and B), and no deviation (backbone) was found in S. aureus AgrA (4G4K), and it prefers a stable $100 \mathrm{~ns}$.

\subsubsection{Molecular dynamics simulations of S. aureus AgrA-AL and SarA-AL complex}

MD simulation of the S. aureus AgrA backbone and ligand AL complex was effected and well equilibrated within the $100 \mathrm{~ns}$ (Figure 5A and B). The ligand AL complex acquires stability with RMSD of $\sim 0.2 \mathrm{~nm}$, and showed stability of the protein backbone in the presence of the ligand. The protein backbone and ligand AL complex possessed a competent docking property observed from the lead IFD scores and when we examined for molecular dynamics simulation, the complex displayed stability by continuing the MD simulations up to $100 \mathrm{~ns}$. Similarly, MD simulations were performed to compare the dynamic behavior and binding stability of the protein-ligand complex (S. aureus SarA-AL) in an environment containing water. The stability of the protein-ligand complex (Figure 5C and D) was studied using MD simulation for $100 \mathrm{~ns}$ using GROMACS. The RMSD (Figure 5D) showed that there was a slight deviation that gradually increased to $\sim 0.5 \mathrm{~nm}$, and later, the protein backbone showed slight fluctuation throughout the simulation period of $100 \mathrm{~ns}$. 

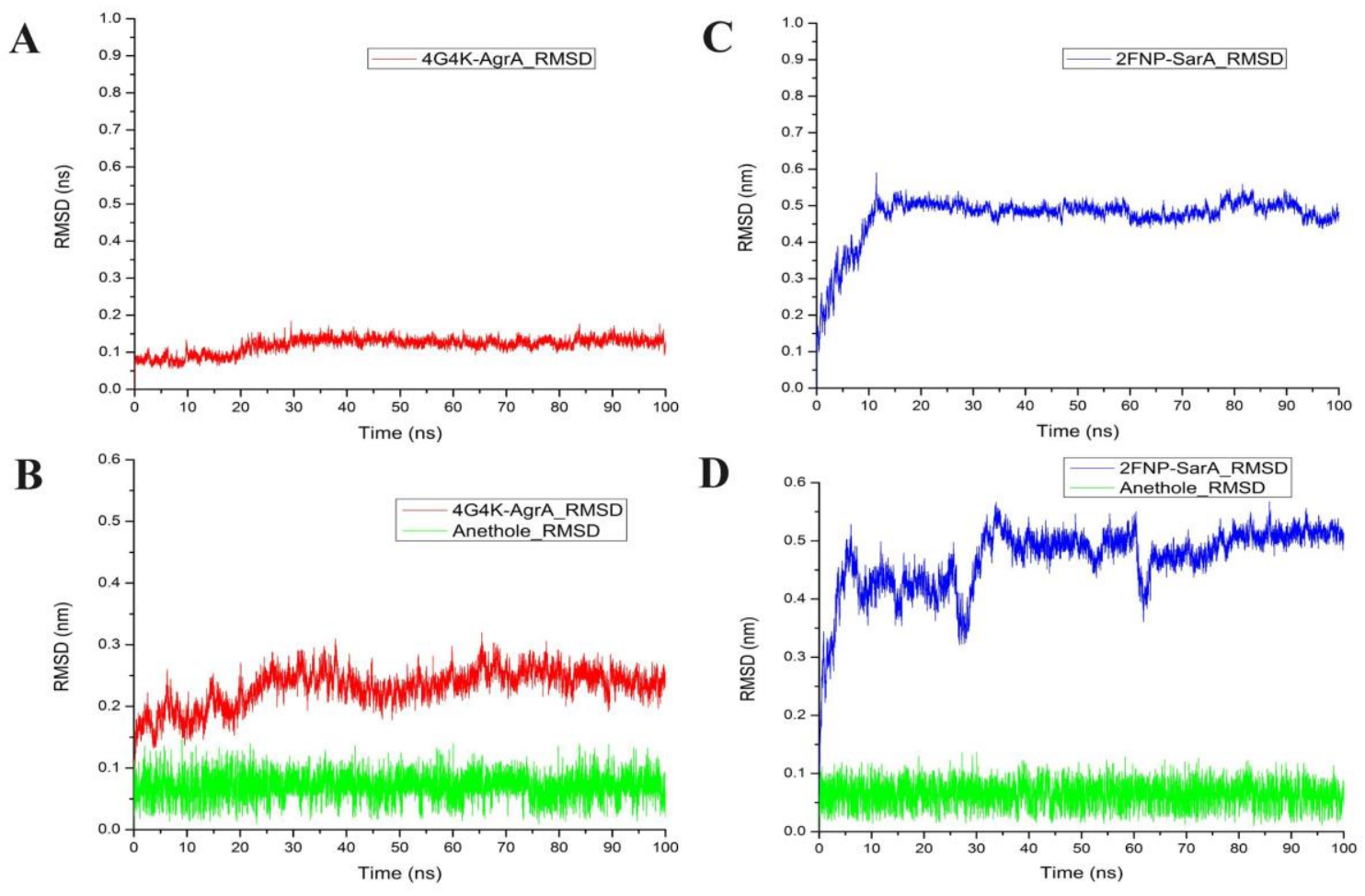

Figure 5: A) RMSD of the backbone of S. aureus AgrA form during the simulation run of 100ns (Red). (B) Backbone RMSD values of ligand (anethole) nominees from the S. aureus AgrA of protein-legend complexes were generated against the initial structures of protein-ligand complexes during $100 \mathrm{~ns}$ of molecular dynamics (MD) simulation period (Green). (C) RMSD of the backbone of S. aureus SarA form during the simulation run of 100ns (Blue). (D) Backbone RMSD values of ligand (anethole) nominees from the $S$. aureus SarA of protein-legend complexes were generated against the initial structures of protein-ligand complexes during 100 ns of molecular dynamics (MD) simulation period (Green).

\section{Discussion}

S. aureus causes nosocomial infections, both in the community and in the hospital environment [16]. Bacterial biofilms play a vital role in disease progression and persistent infections involving the lungs. Establishment of infection and biofilm formation are under the control of QS system [17]. Treatment of biofilm-forming S. aureus infections remains a major challenge in health care settings largely because these pathogenic bacteria are predominantly resistant to conventional antibiotics [18]. In our current study, the clinical MRSA strain SA-01 showed resistance to numerous antibiotics as compared to SA-02. The obtained results are comparable with previous reports by others [19, 20]. The present study also evaluated the antibiofilm activities of I. verum fruit extract the against MRSA (SA-01) strain tested. During primary screening, the methanol extract of I. verum fruit inhibited bacterial growth at a lowest concentration of $5 \mathrm{mg} / \mathrm{ml}$. The present data corroborates with the findings of Mostafa et al. [21] where they reported that the ethanolic extracts of Cuminum cyminum inhibited the growth of MRSA at a concentration of $10 \mathrm{mg} / \mathrm{ml}$. Here, we showed that at sub-MIC concentrations, the fruit extract of I. verum substantially inhibited QS-dependent biofilm formation in the SA-01 strain in a dose-dependent manner. Crystal violet staining assay revealed that treatment with $2.4 \mathrm{mg} / \mathrm{ml}$ of $I$. verum fruit extract showed 
significant reduction in biofilm formation in the tested strain to a level of $74 \%$. Previously, other have shown that Sesbania grandiflora reduced the production of biofilm formation and exopolysaccharide production in S. aureus [22]. Similarly, Payne et al. [23] have reported that tannic acid rich black tea inhibited biofilm formation in a wild type strain of $S$. aureus. Rhodomyrtone compound effectively suppressed biofilm formation in S. aureus (ATCC 25923) in a dose-dependent manner [24]. Agr QSdependent spreading motility plays an important role in the initiation of surface attachment and form biofilm matrix on the surface [25]. Findings from the present study depicted that the methanolic extract of I. verum (fruit) effectively decreased the QS-dependent swarming at a concentration of $2.4 \mathrm{mg} / \mathrm{ml}$ suggesting that methanol extract of I. verum might inhibit swarming either by interacting with Agr QS dependent virulence factors and biofilm formation in clinical isolates tested. At sub-MIC concentration, methanol crude extract of I. verum (fruit) did not inhibit the bacterial growth but only inhibited the QSdependent virulence factors and biofilm formation. The reduction of biofilm matrix in clinical isolates of SA-01 was further confirmed by light microscopy. Hence, we concluded that I. verum (fruit) extract suppresses the QS-dependent virulence factors in SA-01. The reduction of biofilm architecture appears to be due to reduced surface adhesion of biofilm formation. According to Balamurugan et al. [26] Melia dubia root extract drastically reduced biofilm formation in S. aureus determined by confocal laser scanning microscopy. Our GC-MS results revealed that the presence of AL as a major component in the crude extract of I. verum (fruit), which likely might have inhibited the QS system and biofilm formation in the MRSA strain tested.

AgrA and SarA protein cascade plays a paramount role in QS-controlled virulence, biofilm formation and survival in S. aureus [27]. The current study has revealed that the active ligand of (AL) strongly interacted with the active site of $A g r A$ and interaction pattern with active binding energy of 4.692 and $-232.42 \mathrm{kcal} / \mathrm{mol}$, respectively. Similarly, the active ligand (AL) bind efficiently with SarA receptor protein and glide score and IFD energy score of -2.723 and $-258.90 \mathrm{kcal} / \mathrm{mol}$. Hence, the active ligand AL has proven its ability to inhibit the active site of AgrA and SarA receptor binding pocket, and therefore, the active ligand might mimic the up-regulation of QS-controlled virulence factors and biofilm forming genes. Daly et al. [28] have reported that in the molecular docking analysis, $\omega$-hydroxyemodin ligand strongly binds and suppresses the AgrA-DNA interface of S. aureus. Similarly, prenylated diresorcinols compound 1 efficiently interacts with the AgrAc receptor pocket with a binding energy of $5.5 \mathrm{kcal} / \mathrm{mol}$, and actively interacts with the active site of side chain (Thr142, Lys146, Phe182, Asn185Leu189 and Leu192), which indicates that the active ligand strongly mimics the QS system of $S$. aureus [29].

\section{Materials and Methods}

\subsection{Bacterial culture and growth conditions}

The test isolates of S. aureus, SA-01 and SA-02 were obtained from the clinical archives of the Government Theni Medical College and Hospital, Theni, India. The strains were cultivated aerobically in Luria Bertani (LB) broth and were incubated at $37^{\circ} \mathrm{C}$ for $24 \mathrm{~h}$ in a rotary shaker $(100 \mathrm{rpm})$ prior to use in the experiments. Preliminary identification of the strains as $S$. aureus was based on standard microbiological investigations such as Gram staining, colony morphology, texture, yellow pigmentation characteristic growth pattern on mannitol salt agar, coagulase, oxidase, catalase, motility, temperatures, citrate, indole, methyl red, Voges Proskauer, nitrate reduction test, gelatin hydrolysis, $\mathrm{H}_{2} \mathrm{~S}$ test and $\mathrm{pH}$ as described by others [30, 31]. 


\subsection{Disk diffusion assay}

S. aureus (SA-01 and SA-02) were sub-cultured in LB broth and incubated at $37^{\circ} \mathrm{C}$ in shaker incubator. Optical density (OD) was adjusted to $0.5 \mathrm{McF}$ arland $\left(1 \times 10^{8} \mathrm{CFU} / \mathrm{ml}\right)$ standards. Cultures were swabbed on the surface of Muller Hinton Agar (MHA-Himedia, India) plates. Selected antibiotic discs (Himedia, India) were gently placed on the center of the agar plates, incubated at $37^{\circ} \mathrm{C}$ for $18-24 \mathrm{~h}$. Zone of inhibition was measured using a standard scale (Himedia, India), and results were analyzed by standard deviation. The test was performed in triplicates and results were interpreted according to the Clinical and Laboratory Standards Institute (CLSI) guidelines [32].

\subsection{Preparation of star anise (I. verum) fruit}

Dry star anise (I. verum) was procured from the local supermarket, and the collected I. verum fruits (Accession no: CUTN/DLS/IMM/001/2019) were confirmed taxonomically by consulting with a certified taxonomist. Fruits (I. verum) were washed thrice with sterile distilled water, dipped in $0.1 \%$ mercury chloride solution for one minute, dried under shade, grounded to a coarse powder by mechanical grinder. Coarse powder of $20 \mathrm{gm}$ was added to $100 \mathrm{ml}$ of methanol and extraction was constantly agitated in shaker for $48 \mathrm{~h}$. Extract was filtered with a Whatman number 1 filter and dried using the rotary flash evaporator in a hot condition of $50^{\circ} \mathrm{C}$. Crude extract was further dried by vacuum concentrate; extract was stored at $4^{\circ} \mathrm{C}$ for further analysis.

\subsection{Determination of minimum inhibitory concentration}

Minimum inhibitory concentration (MIC) for the test extract was determined as per the guidelines of CLSI, [33]. Briefly, $10 \mu \mathrm{l}$ of test pathogen (MRSA) was added to LB broth supplemented with I. verum fruit extract ranging from $0.01875-9.6 \mathrm{mg} / \mathrm{ml}$ (serial two-fold dilution) and without extract (control). All the tubes were incubated at $37^{\circ} \mathrm{C}$ for $24 \mathrm{~h}$. MIC was recorded as the lowest concentration at which there was no visible growth. Further, QS-controlled virulence factors and biofilm assay were performed at sub-MIC concentrations of the fruit extract.

\subsection{Growth analysis}

Growth curve for MRSA culture in the presence as well as absence of I. verum fruit (crude extract) was analyzed. Briefly, overnight culture of MRSA was inoculated into $100 \mathrm{ml}$ of LB broth with I. verum fruit extract (treated) and without I. verum fruit extract (control), incubated in a shaker incubator at $37^{\circ} \mathrm{C}$

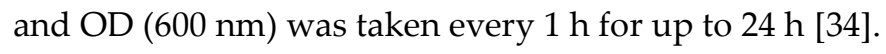

\subsection{Biofilm inhibition assay}

Overnight culture (OD adjusted to 0.4 at $600 \mathrm{~nm}$ ) of the test strain (MRSA) was inoculated into Tryptic Soy Broth (TSB) with and without the crude extract of $I$. verum fruit ranging from $0.3-2.4 \mathrm{mg} / \mathrm{ml}$ in microtitre plate, incubated at $37^{\circ} \mathrm{C}$ for $24 \mathrm{~h}$. After $24 \mathrm{~h}$, planktonic cells were removed without disturbing the biofilm and read at $600 \mathrm{~nm}$. Crystal violet $(10 \mu \mathrm{l}, 0.1 \%(\mathrm{w} / \mathrm{v})$ in water) was added into the each well, incubated for $15 \mathrm{~min}$ at room temperature. Crystal violet was removed from the wells and gently washed with sterile distilled water to remove the unbound stain. Finally, the adhered biofilm bounded crystal violet was eluted in ethanol (95\%) and the absorbance was measured at $595 \mathrm{~nm}$ (BioRad, Japan). Presence of growth (planktonic cells) of treated MRSA was compared with that of untreated control strain by measuring the OD $600 \mathrm{~nm}$ [34]. 


\subsection{Swarming motility assay}

To the Luria Bertani (LB) plates supplemented with glucose $(0.075 \mathrm{~g} / 15 \mathrm{ml} \mathrm{LB}$ broth), $2.4 \mathrm{mg} / \mathrm{ml}$ of I. verum fruit extract in $5 \mathrm{ml}$ of sterile LB agar (supplemented with glucose $0.025 \mathrm{~g} / 0.5 \%$ agar) and without extract (control) were overlaid. Overnight culture of MRSA (SA-01) was adjusted to $1 \times 108 \mathrm{cells} / \mathrm{ml}$, inoculated as a single spot on the center of the LB plates (with/without extract), incubated at $37^{\circ} \mathrm{C}$ for $24 \mathrm{~h}$ $[34,35]$.

\subsection{In situ visualization of S. aureus}

\subsubsection{Light microscopy analysis}

Overnight culture (OD adjusted to 0.4 at $600 \mathrm{~nm}$ ) of MRSA was inoculated into Tryptic Soy Broth (TSB) along with and without extract. Cover slips were placed on the center of the plates carefully avoiding air bubbles. After $18 \mathrm{~h}$ of incubation, cover slips were removed from plates using sterile forceps, gently rinsed thrice with phosphate buffer solution (PBS) to remove unbound planktonic cells. Adhered biofilm was stained with $0.1 \%$ crystal violet $(\mathrm{CV})$ solution and visualized under light microscope at magnifications of 40X (Olympus CH20i, Noida).

\subsection{Gas chromatography and mass spectroscopy analysis}

GC-MS analysis of the crude extract (I. verum fruit) was performed by an Agilent 5977E using HP-5MS ultra-inert $(30.0 \mathrm{~m} \times 250 \mu \mathrm{m} \times 0.25 \mu \mathrm{m})$ fused silica capillary column. Helium was used as carrier gas at a constant flow rate of $0.8 \mathrm{ml} / \mathrm{min}$. Crude extract was dissolved in methanol and $1 \mu \mathrm{l}$ of the sample was injected (spilt ratio 100:1) into the GC-MS using AOC5000 auto injector for analysis. Identification of volatile organic constituents was confirmed by published electron impact-mass spectra (EI-MS) in the National Institute for Standard and Technology (NIST).

\subsection{In silico analysis of antibiofilm activity of I. verum and its constituent anethol (AL)}

Entire induced fit docking (IFD) and molecular dynamics (MD) simulations were performed using high performance computing (HPC) cluster operated with CentOS V6.5 Linux operating system using Schrödinger suite 2019-2with graphical user interface Maestro and GROMACS 5.1.4 package [3638] . Hardware specifications of HPC cluster master node are IBM X3550M4 1U Rack server with dual Intel Xeon E5-2670 V2 10c $2.5 \mathrm{GHz}$ processors with 128 GB of Memory.

\subsubsection{Preparation of AgrA and SarA Proteins}

X-ray crystal structures of S. aureus AgrA (PDB ID: 4G4K) and S. aureus SarA (PDB ID: 2FNP) were downloaded from Protein Data Bank (PDB) [39, 40]. Prior to docking, protein structures were prepared using Protein Preparation Wizard of Schrödinger suite 2019-2 with graphical user interface Maestro [41, 42]. Water molecules and other components from the crystal configuration were removed. For evaluation of structure and bond order assigned, hydrogen atoms were included to the four parent carbon atoms. Hydrogen bonds assignment device was utilized to improve the hydrogen bond network. Impact refinement module optimized position of hydrogen bonds by keeping all the atoms in place. Minimization was terminated when root mean square deviation (RMSD) of heavy atoms in the default limitation of $0.3 \AA$ of RMSD and OPLS3e force field which produce the lowest energy conformer of protein structure used in following IFD study [43]. 


\subsubsection{Receptor binding site and grid generation}

Refined and optimized protein structures processed using SiteMap module of Schrödinger suite to specify the location of receptor site, using options to report maximum 5 sites that requires at least 15 site points using more restrictive definition of hydrophobicity with standard grid cropping site maps at $4 \AA$ from nearest site point. SiteMap module generated possible potential receptor site in the receptors ( $S$. aureus AgrA and SarA) with quantitative site-score values for each site which considers size, enclosure, exposure, contacts, hydrophobicity, hydrophilicity and Hbond donor acceptor balance. Drug ability site based on the top ranked sit score in SiteMap was prearranged as Glide input file and receptor grid generation was carried out with white colored spheres along the protein. Receptor grid box for carrying out molecular docking was set to active site residues, which are as cited in SiteMap site one were used as a centroid for generating Glide receptor grid generation (with automatic setting of enclosing box) using Van der Waals scaling setup of 0.8 and partial charge cutoff of 0.25 with centroid of grid as selected residues [44, 45].

\subsubsection{Ligand preparation}

Structure of AL (CID 637563) used for the study, retrieved from NCBI - PubChem database is shown in Table 1. Preparation of ligands using LigPrep wizard of Schrödinger includes 2D-3D structure conversion and generation of Epik model was used to generate ligand protonation states in a $\mathrm{pH}$ range of $7.0 \pm 2.0$ [46]. Molecules were optimized using OPLS3e force field.

\subsubsection{Induced Fit Docking (IFD)}

IFD was done to introduce the flexibility for both receptors and ligand during Glide docking. This was proficient by consolidating a various iteration of docking of flexible ligand into inflexible receptor pursued by refinement of active site of protein to adopt the conformation appropriate for a given ligand $[47,48]$. In the first step of docking, ligand was docked to protein using initial Glide docking program with Van der Waals radii scaling of $0.5 \AA$. Resulting top 20 poses used in second step to refine

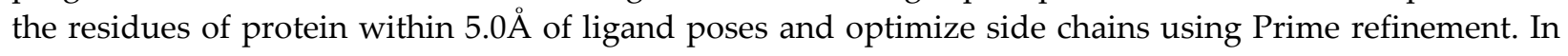
the third step, top 20 new receptor conformations were taken for glide redocking and Glide XP (extra precision) used for docking calculations. Finally, along with receptor and solvation terms, binding energy associated with each pose was utilized for scoring [49]. Further, the docked proteins-ligand complex was subjected to molecular dynamics (MD) simulations to evaluate the stability of proteins-ligand docked complex.

\subsubsection{Molecular Dynamics (MD) Simulations}

MD simulations were performed on the AgrA, AgrA - AL, SarA, SarA-AL composites using the GROMACS 5.1.4 package [38]. Proteins ( $\operatorname{Arg} A$ and $\operatorname{Sar} A)$ topology files generated using automated topology builder (ATB) in the framework of GROMOS96 $53 a 6$ force field for protein $(\operatorname{Arg} A$ and $\operatorname{Sar} A)$ ligand (AL) complex $[50,51]$. The charges of ligand (AL) topology files were generated using PRODRG 2.5 server [52]. Ligand complex obtained from docking was solvated with single point charge (SPC) water model [53]. The final system was minimized using the steepest descent algorithm. This step was followed by 1 nano second (ns) MD simulation, where S. aureus AgrA and SarA with AL complexes were position restrained to equilibrate water and ions under the influence of solute. Production run carried out for all the systems for 100 ps using 2 fs time step for integration of equation of motion in the NPT (isothermalisobaric) ensemble at $300 \mathrm{~K}$ and at 1 atmospheric pressure, which was controlled using a V-rescale 
thermostat and Parrinello-Rahman Barostat, respectively. Bond lengths involving hydrogen atoms were constrained using Linear Constraint Solver (LINCS) algorithm [54]. The Particle Mesh Ewald (PME) method was applied to calculate electrostatic interaction [55, 56]. Cutoff distances for long-range electrostatic and van der Waals energy terms were set as $10 \AA$ A. Finally MD run was set to $100 \mathrm{~ns}$ for each protein-ligand complex and coordinates of all the systems were saved at 2 ps interval for further analyses. Post processing and analyses were carried out using GROMACS analysis tools. MD trajectories analyzed using gmx rms utilities of GROMACS package to obtain the Root Mean Square Deviation (RMSD).

\subsubsection{Statistical analysis}

All experiments (In vitro) were performed in triplicates. Statistical significance for quantification of biofilm was determined by one-way ANOVA using software GraphPad Prism 5.03

\subsection{Conclusions}

In conclusion, based on the obtained results obtained through in vitro and in situ analyses of antibiofilm activity of I. verum against MRSA and in silico analysis of molecular docking studies binding relationship of AL compound with Agr/Sar QS system, the reduced QS-controlled virulence factors and biofilm formation of MRSA appears to be due to the inhibitory properties of AL necessitated by suppressing the AgrA and SarA receptor proteins of MRSA. Our data suggest that I. verum fruit extract and its active constituent AL alone or combination with anti-infective agents could be beneficial against biofilm-forming MRSA infections, which remains to be tested further.

Supplementary Materials: The following are available online at www.mdpi.com/xxx/s1, Table S1 and S2:

Author Contributions: Conceptualization, P.S.G., E.M.S., and V.K.; methodology, P.S.G., K.I., and V.K.; software, S.S.; validation, P.S.G., E.M.S., V.R.A., D.C., S.Sh., S.N., and S.S.; formal analysis, P.S.G., I.V.J., V.R.A., D.C., S.S., and S.N..; investigation, P.S.G., E.M.S., S.S., and V.K.; resources, V.R.A., D.C., S.S., S.N., and S.Sh.; data curation, V.R.A., D.C., S.S., E.M.S., and S.Sh.; writing-original draft preparation, P.S.G., E.M.S., and V.K.; writing-review and editing, E.M.S.; visualization, S.S., P.S.G.; supervision, P.S.G., and E.M. S.; project administration, E.M.S.; funding acquisition, E.M.S.

Funding: This research received no external funding.

Conflicts of Interest: The authors declare no conflict of interest.

\section{References}

1. Thomer, L.; Schneewind, O.; Missiakas, D. Pathogenesis of Staphylococcus aureus bloodstream infections. Annu. Rev. Pathol. 2016, 11, 343-364.

2. David, M.Z.; Daum, R.S. Community - associated methicillin resistant Staphylococcus aureus: Epidemiology and clinical consequences of an emerging epidemic. Clin. Microbiol. Rev. 2010, 23, 616-687.

3. Yadav, M.K.; Chase, S.W.; Go,Y.Y.; Im, G.J.; Song, J.J. In vitro multi-species biofilms of methicillin-resistant Staphylococcus aureus and Pseudomonas aeruginosa and their host interaction during in vivo colonization of an otitis media rat model. Front. Cell. Infect. Microbiol. 2017, 7, 125.

4. Percival, S.L.; Suleman, L.; Vuotto, C.; Donelli, G. Healthcare -associated infections, medical devices and biofilms: risk, tolerance and control. J. Med. Microbiol. 2015, 64, 323-334.

5. Chanbers, H.F.; Deleo, F.R. Waves of resistance: Staphylococcus aureus in the antibiotics era. Nat. Rev. Microbiol. 2009, 7, 629-41. 
6. Goldmann, O.; Medina, E. Staphylococcus aureus strategies to evade the host aquired immune response. Int. J. Med. Microbiol. 2018, 308, 625-630.

7. Miller, M.B.; Bassler, B.L. Quorum sensing in bacteria. Annu. Rev. Microbiol. 2001, 55, 165-99.

8. Thoendel, M.; Kavanaugh, J.S.; Flack, C.E.; Horswill, A.R. Peptide signaling in the staphylococci. Chem. Rev. 2011, 111, 117-151.

9. Archer, N.K.; Mazaitis, M.J.; Costerton, J.W.; Leid, J.G.; Powers, M.E.; Shirtliff, M.E. Staphylococcus aureus biofilms properties, regulation and roles in human disease. Virulence. 2011, 2, 445-459.

10. Chung, P.Y.; Toh, Y.S. Anti-biofilm agents: recent breakthrough against multi-drug resistant Staphylococcus aureus. Pathog. Dis. 2014, 70, 231-239.

11. Paharilk, A.E.; Horswill, A.R. The staphylococcal biofilm: adhesins, regulation, and host response. Microbiol. Spectrum. 2016, 4.

12. Bjarnsholt, T. The role of bacterial biofilms in chronic infections. APMIS. 2013, 12, 1-58.

13. Cowan, M.M. Plant products as antimicrobial agents. Clin. Microbial. Rev. 1999, 12, 564-582.

14. Fritz, E.; Olzant, M.S.; Langer, R. Illicium verum Hook.f. and Illicium anisatum. L anatomical characters and their value for differentiation. Sci. Pharm. 2008, 76, 65-76.

15. Vecchio, M.G.; Gulati, A.; Minto, C.; Lorenzoni, G. Pimpinella anisum and Illicium verum : The multifaceted role of anise plants. The. Open. Agri. J. 2015, 10, 81-86.

16. Defres, S.; Marwick, C.; Nathwani, D. MRSA as a cause of lung infection including airway infection, community-acquired pneumonia and hospital-acquired pneumonia. Eur. Respir. J. 2009, 34, 1470-1476.

17. Balaban, N.; Cirioni, O.; Giacometti, A.; Chiselli, R.; Braunstein, J.B.; Silvestri, C.; Mocchegiani, F.; Saba, V.; Scalise, G. Treatment of Staphylococcus aureus Biofilm Infection by the Quorum-Sensing Inhibitor RIP. Antimicrob. Agents. Chemother, 2007, 51, 2226-2229.

18. Rubinstein, E.; Kollef, M.H.; Nathwani, D. Pneumonia caused by methicillin resistant Staphylococcus aureus. Clin. Intect. Dis. 2008, 46, S378-S385.

19. Joshi, S.; Ray, P.; Manchanda, V.; Bajaj, J.; Chitnis, D.S.; Gautam, V.; Goswami, P.; Gupta, V.; Harish, B.N.; Kagal, A.; Kapil, A.; Rao, R.; Rodrigues, C.; Sardana, R.; Devei, Kh.S.; Sharma, A.; Balaji, V. Methicillin resistant Staphylococcus aureus (MRSA) in India: Prevalence \& susceptibility pattern. Indian J. Med. Res. 2013, 137, 363-369.

20. Gitau, W.; Masika, M.; Musyoki, M.; Museve, B.; Mutwiri, T. Antimicrobial susceptibility pattern of Staphylococcus aureus isolates from clinical specimans at Kenyatta National Hospital. BMC. Res. Notes. 2018, $11,226$.

21. Mostafa, A.A.; Al-Askar, A.A.; Almaary, K.S.; Dawoud, T.M.; Sholkamy, E.N.; Bakri, M.M. Antimicrobial activity of some plant extracts against bacterial strains causing food poisoning diseases. Saudi. J. Biol. Sci. 2018, 25, 361-366.

22. Gandhi, A.D.; Vizhi, D.K.; Lavanya, K.; Kalpana V.N.; Rajeswari, V.D.; Babujanarthanam, R. In vitro antibiofilm and anti-bacterial activity of Sesbania grandiflora extract against Staphylococcus aureus. B.B. Reports. 2017, 12, 193-197.

23. Payne, D.E.; Martin, N.R.; Parzych, K.R.; Rickard, A.H.; Underwood, A.; Boles, B.R. Tannic acid inhibits Staphylococcus aureus surface colonisation in an IsaA- dependent manner. Infect. Immun. 2013, 81, 496-504.

24. Saising, J.; Ongsakul, M.; Voravuthikunchai, P.P. Rhodomyrtus tomentosa (Aiton) Hassk. ethanol extract and rhodomyrtone: a potential strategy for the treatment of biofilm-forming staphylococci. J. Med. Microbiol. 2011, 60, 1793-800.

25. Ueda, T.; Kaito, C.; Omae, Y.; Sekimizu, K. Sugar-responsive gene expression and the agr system are required for colony spreading in Staphylococcus aureus. Microb. Pathog. 2011, 51, 178-185. 
26. Balamurugan, P.; Hema, M.; Kaur, G.; Sridharan, V.; Prabu, P.C.; Sumana, M.N.; Princy, S.A. Development of a biofilm inhibitor molecule against multidrug resistant Staphylococcus aureus associated with gestational urinary tract infections. Front. Microbiol. 2015, 6, 832.

27. Novick, R.P.; Geisinger, E. Quorum sensing in staphylococci. Annu. Rev. Genet. 2008, 42, 541-64.

28. Daly, S.M.; Elmore, B.O.; Kavanaugh, J.S.; Triplett, K.D.; Figueroa, M.; Raja, H.A.; El-Elimat, T.; Crosby, H.A.; Femling, J.K.; Cech, N.B.; Horswill, A.R.; Oberlies, N.H.; Hall, P.R. $\omega$-Hydroxyemodin limits Staphylococcus aureus quorum sensing -mediated pathogenesis and inflammation. Antimicrob. Agents. Chemother. 2015, 59, 2223-2235.

29. Paguigan, D.; Chavez, J.R.; Stempin,;J.J. Augustinović, M.; Noras, A.I.; Raja, H.A.; Todd, D.A.; Triplett, K.D.; Day, C.; Figueroa, M.; Hall, P.R.; Cech, N.B.; Oberlies, N.H. Prenylated diresorcinols inhibits bacterial quorum sensing. J Nat Prod 2019; 82: 550-558.

30. Patricia, M.T.; Bailey and Scottis Diagnostic Microbiology, MOSBY, St. Louis: Elsevier, 2014

31. Lancette, G.A.; Tatini, S.R. "Staphylococcus aureus," in Compendium of Methods for the Microbiological Examination of Foods, C. Vanderzant and D. F. Splittstoesser (ed.). American Public Health Association, Washington, DC, USA, 3rd edition, 1992, 533-550.

32. Clinical Laboratory Standards Institute. Performance Standards for Antimicrobial Susceptibility Testing: Eighteenth Informational Supplement. Clinical Laboratory Standards Institute; Wayne, PA, USA: 2014. CLSI Document M100-S18.

33. Clinical and Laboratory Standards Institute. Susceptibility testing of mycobacteria, Norcardiae, and Other Aerobic Actinomycetes; Approved Standard. Wayne, Pa. USA: CLSI; 2003. CLSI document M24-A.

34. Ganesh, P.S.; Rai, R.V. In vitro antibiofilm activity of Murraya koenigii essential oil extracted using supercritical fluid CO2 method against Pseudomonas aeruginosa PAO1. Nat. Prod. Res. 2015, 29, 2295-2298.

35. Borges, A.; Saavedra, M.J.; Simões, M. The activity of ferulic and gallic acids in biofilm prevention and control of pathogenic bacteria. Biofouling. 2012, 28, 755-767.

36. Schrödinger Suite 2019-2, Schrödinger, LLC, New York, NY, 2019.

37. Schrödinger Release 2019-2: Maestro, Schrödinger, LLC, New York, NY, 2019.

38. Abraham, M.J.; van der Spoel, D.; Lindahl, E.; Hess, B.; and the GROMACS development team, GROMACS User Manual version 5.1.4, www.gromacs.org, 2016.

39. Leonard, P.G.; Bezar, I.F.; Sidote, D.J.; Stock, A.M. Identification of a hydrophobic cleft in the LytTR domain of AgrA as a locus for small molecule interactions that inhibit DNA binding. Biochem. 2012, 51, 10035-43.

40. Liu, Y.; Manna, A.C.; Pan, C.H.; Kriksunov, I.A.; Thiel, T.J.; Cheung, A.L.; Zhang, G. Structural and function analyses of the global regulatory protein SarA from Staphylococcus aureus. Proc. Natl. Acad. Sci. U S A. 2006, $103,2392-7$.

41. Protein Preparation Wizard; Epik, Schrödinger, LLC, New York, NY, 2019; Impact, Schrödinger, LLC, New York, NY, 2019; Prime, Schrödinger, LLC, New York, NY, 2019.

42. Sastry, G.M.; Adzhigirey, M.; Day T,; Annabhimoju, R.; Sherman, W. Protein and ligand preparation: parameters, protocols, and influence on virtual screening enrichments. J. Comput. Aided. Mol. Des. 2013, 27, 221-34.

43. Harder, E.; Damm, W.; Maple, J.; Wu, C.; Reboul, M.; Xiang, J.Y.; Wang, L.; Lupyan, D.; Dahlgren, M.K.; Knight, J.L.; Kaus, W.J.; Cerutti, D.S.; Krilov, G.; Jorgensen, W.L.; AbelR.; Friesner, R.F. OPLS3: A force field providing broad coverage of drug-like small molecules and proteins. J. Chem. Theory. Comput. 2016, 12, 281-96.

44. Halgren, T. New method for fast and accurate binding-site identification and analysis. Chem. Biol. Drug. Des. 2007, 69, 146-8. 
45. Halgren, T.A. Identifying and characterizing binding sites and assessing druggability. J. Chem. Inf. Model. $2009,49,377-89$.

46. Shelley, J.C.; Cholleti, A.; Frye, L.L.; Greenwood, J.R.; Timlin, M.R.; Uchimaya, M. A software program for $\mathrm{pK}$ ( a ) prediction and protonation state generation for drug-like molecules. J. Comput. Aided. Mol. Des. 2007, 21, 681-91.

47. Schrödinger Release 2019-2: Schrödinger Suite 2019-2 Induced Fit Docking protocol; Glide, Schrödinger, LLC, New York, NY, 2019; Prime, Schrödinger, LLC, New York, NY, 2019.

48. Farid, R.; Day, T.; Friesner, R.A.; Pearlstein, R.A. New insights about HERG blockade obtained from protein modeling, potential energy mapping, and docking studies. Bioorg. Med. Chem. 2006, 14, 3160-73.

49. Sherman, W.; Day, T.; Jacobson, M.P.; Friesner, R.A.; Farid, R. Novel procedure for modeling ligand/receptor induced fit effects. J. Med. Chem. 2006, 49, 534-53.

50. Oostenbrink, C.; Villa, A.; Mark, A.E.; van Gunsteren, W.F. A biomolecular force field based on the free enthalpy of hydration and solvation: the GROMOS force-field parameter sets 53A5 and 53A6. J. Comput. Chem. 2004, 25, 1656-1676.

51. van Gunsteren, W.F.; Billeter, S.R.; Eising, A.A.; H“unenberger, P.H.; Kr"uger, P.; Mark, A.E.; Scott, W.R.P.; Tironi, I.G. Biomolecular Simulation: The GROMOS96 Manual and User Guide Vdf Hochschulverlag AG an der ETH Z“urich, Z“urich, Switzerland, 1996, pp. 1-1042

52. Schüttelkopf, A.W.; van Aalten, D.M. PRODRG: a tool for high-throughput crystallography of proteinligand complexes. Acta Crystallogr D Biol Crystallogr. 2004, 60, 1355-63.

53. Berendsen, H.J.C.; Postma, J.P.M.; van Gunsteren, W.F.; Hermans, J. Interaction models for water in relation to protein hydration in Intermolecular Forces Pullman, B, (ed.), Reidel, Dordrecht, 1981.

54. Hess, B.; Bekker, H.; Berendsen, H.J.; Fraaije, J.G. LINCS: A linear constraint solver for molecular simulations. J. Comput. Chem. 1997, 18, 1463-1472.

55. Essmann, U.; Perera, L.; Berkowitz, M.L.; Darden, T.; Lee, H.; Pedersen, L.G. A smooth particle mesh Ewald method. J. Chem. Phys. 1995, 103, 8577-8593.

56. Darden, T.; York, D.; Pedersen, L. Particle Mesh Ewald-an N.Log (N) method for Ewald sums in large systems. J Chem Phys 1993; 98: 10089-10092. 